\title{
Attendance System Using NFC Technology with Embedded Camera on Mobile Device
}

\author{
Abhilash Bhise ${ }^{1}$, Radhika Khichi ${ }^{2}$, Amol Korde ${ }^{3}$, Prof. Deepali Lokare ${ }^{4}$ \\ B.E Final year, Sinhagad Institute of Technology, Lonavala, Maharashtra, India ${ }^{1,2,3}$ \\ Assistant Professor, Computer Engg.,dept., Sinhagad Institute of Technology, Lonavala, Maharashtra, India ${ }^{4}$
}

\begin{abstract}
In most of the university and colleges attendance of students is important factor, checking student attendance is the important issues because all universities evaluate student's attendance while them giving final grade. Some colleges use paper sheet for student attendance and after that fill all this information manually in college server. This all are time consuming process like calling particular student then fill all information, and student give the proxies of their friends even they absent. By considering all this issue we develop one system which get attendance and update attendance in one place. Our paper presents near field communication technology to get the attendance of students in school and colleges. The system is based on NFC Technology and run on mobile as application, this paper presented details of this system.
\end{abstract}

Keyword: attendance, near field communication, android OS, embedded mobile camera

\section{INTRODUCTION}

This paper introduces a Near Field Communication (NFC) supported collage attendance system for college students. In the most of collages lecturer take attendance by calling out the names and surnames of students and then marking them or pass the attendance sheet to students and asking students to sign in attendance sheet. This both practices have their drawbacks. In first case if strength of students are more, checking all these student by name and surname might take about several minutes. In second case if student is absent then friends of absent students may write down their name and surnames. These practices place college institutions at considerable disadvantages when it comes to taking attendance. To come out from all these issues we put NFC tag into service. Each tag has a unique ID, precluding the duplication of a tag. These NFC tag are given to students when they registered in college. When student enter in class rooms and touch or move these tag on lecturer mobile phone, NFC readers program will read these tags, identify the students from their respective NFC tag and embedded camera will capture the face of particular student then application send all the data to college server and in server side validation program will check the data for validation (compare new data with previous data which was already store in database) if valid data found then program will update the database as marking attendance otherwise mark student is absent. These all done with one system no manual working this means no class time will be wasted.

\section{A. FUNDAMENTAL CONCEPT ON (DOMAIN):}

NFC near- field communication, is an easy and intuitive technology that allows user to use the user's mobile phone for special purposes. We use this technology for make communication in between two devices, mobile and NFC tag. NFC reader will read the data from the respective NFC tag and embedded camera capture the students face and application will send this information to the college server for validation.
In server side program will check for validation and component analysis algorithm compare temporary image with the original image. If data are valid then programmed update the database, otherwise close application by showing an error message.

\section{A. CONTRIBUTIONS:}

NFC is a short range radio technology that enables communication between two NFC enabled devices. When NFC compatible devices are brought together less than four centimeters or touching the device then communication occurs.

It operates at $13.56 \mathrm{MHz}$ and transfer data up to $424 \mathrm{Kbits}$ per second [1]. Now a days there are many techniques available to establish communication in the two devices. But in our system we need technique which works in very short range and not required pairing of devices because it is not possible for every student to pair own tag with mobile. The main advantages of the NFC are the simple and quick way of using it and the speed of connection establishment.

NFC is based on existing radio frequency communication standards, so it is a special case of implementation of RFID technology. It uses the NFC reader to read the information. The touch-paradigm prevents reading from a long distance because a short physical proximity is needed to transfer information.

It is possible to read the information through NFC from long distance with special powerful reader devices. In our system we explore a usage scenario where NFC-enabled mobile phone located in the classrooms are used to read information stored on students NFC cards. 


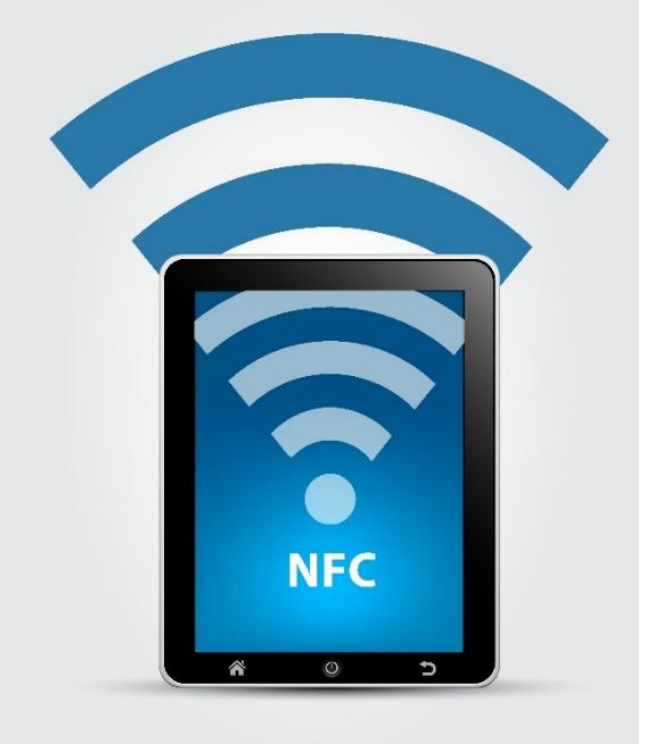

Fig. 1. Sample of NFC Enabled Device

\section{LITERATURE SURVEY}

\section{A. EXISTING SYSTEM}

The survey paper gives an overview about NFC which is use in attendance system, but by compare temporary image with the original image. If data are valid then programmed update the database, otherwise close application by showing an error message. Only using NFC reader lecturer need for manual monitoring. The working is fast in case of enrolling student, but every time lecturer need to see particular student and keep watch here security is less and efforts is more.

\section{B. SOLUTION:}

\section{CONFLICT:}

When a student enters in classrooms, they place or move NFC tag near NFC enabled mobile phone NFC reader will read the data from NFC tag. If someone has their friends' tag in such condition, we need unique info about student like fingerprint Biometrics, Iris recognitions, face recognitions etc., which is guanine info of student that no one copied it.

\section{SUBSTITUTION:}

In this paper, we propose to build a system with one server and all mobile phones are connected to this server. The data will be saved in one database on mobile phone and send it to the database on the server. All lecturers must have an NFC enable mobile phone and NFC embedded reader that can read the student NFC tag. When a student move NFC tag near mobile phone, then the application will on the embedded camera device that can take their photos. We use this technique to prevent a student from giving his/her NFC tag with classmate friends, touch the other student's NFC tag to make it he/she also attended the class.

\section{RELATED WORK}

Today there will lots of Developments in network and mobile technologies. It provides us lots more methods for supporting children in their transition between home and school [3]. For example, To know the children are safe or not on their way to school the location system is the best option [4]. Jernstroms [4] introduces a solution called The Smart-its child Surveillance System, SiSSy, This approach tag children and their parents with Smart-Its devices which can determine whether thesituation is dangerous or if the child is suffering in difficulties.In a study by Fraser et al. [3], family members saw journeys between home and school as an important transition and a big issue for parents in managing their children's time.Information transfer between home and school was also raised as an important matter.Families' reactions to home school technologies were showing excitement, they saw benefits in the increased availability of information that can be obtain through these technologies. While parents were worried about their children's they suggested that technologies that monitored children's activities, such as the mobile phone tracker and sensors, moved from expressing concern to expressing doubt about children aged.In consequence, Fraser et al. identified as one core issue for future research the discussion of children's privacy in technological design.

Not only are there safety concerns about the protection of data collected about children in gathering it. For example, increasing links between home and school then how we clear it when children are often active in resisting such transfer information [5]?

Denmark is traditionally presented as a country where children are able to freely move around and have independent quality of moving freely to schools and leisure facilities [11], and Finland can be considered similar to Denmark when it comes to children's mobility. Children beginning school in Finland travel to school largely independently, either on foot, by bicycle, or bus. A Danish survey by Fotel and Thomsen [11] states that parents' supervision of children's mobility is bound up with different aspects of their travel conditions, such as the choice of mode of transport. Driving a child, for instance, clearly supports the physical supervision of children's mobility, whereas bicycling or walking can be performed by the child on his/her own and thus leaves room for unmonitored movement.

While statistics show a reduction in the number of road accidents involving children during the past decades, Danish parents report an increase in their concerns about their children's road safety [12]. Ontop of monitoring children's mobility through escorting them by car or other traffic modes, some Danish parents also monitor their children's mobility from a distance [11]. New technology has made it possible to monitor children by e.g.. Their cellular phones, and some parents use that deliberately of where they can go independently. Monitoring children's movements from a distance seems to provide some parents with a feeling of control and thus seems to ease their risk worries, even though parents' opportunities to save the child from any danger are limited [11]. Fotel and Thomsen [11] state that even though monitoring the mobility of children is often done with a caring rationality, it can transform into a control, which in some cases, the child does not benefit from. 
IV.

\section{PROPOSED SYSTEM}

- We are using NFC Technology for reading the student tag. Student tag contains information like roll no, name id etc.

- $\quad$ We handle the issue of wastage of time in calling student by establishing distributed work in one place.

- We will handle the issues according to their priorities.

- We minimize the concept of manual monitoring work by including face recognition concept.

\section{IMPORTANT COMPONENTS (MODULES) A. ADMIN}

The admin has complete control of the application and he/she is the person who responsible for governing vital functionalities in the application. We have the web interface in which admin have main role. The different rights bestowed on an admin are as follows:

\section{Teachers and Parents Registration}

The admin is responsible for creating entries for the teachers and parents in the application. During the registration process, the admin enters important details related to them and creates their login credentials in the system.

\section{Student Creation}

The admin is also perform the function like creation of different student in the application.

\section{3. $\quad$ Face Training (JAVA+JSP)}

The student store image will be uploaded by the admin using browser to the face training module which will be stored for detection purposes.

\section{Student, Teachers and Parents mapping}

Using this module, the admin maps the student and their parents and teachers in the application. Likewise admin also issues a NFC tag to students which would be used for their attendance process.

\section{B. ATTENDANCE MARKING \\ 1. Attendance Mobile (Mobile App Android)}

The android mobile phone acts as an attendance machine in our application. IT is using this mobile through which the student will be marked in the class.

\section{Start Attendance}

The teacher will have the NFC enabled mobile phone on which she'll run our application. On successful validation, she would trigger the feature of start attendance. During this phase students need to come forward to mark their attendance.

\section{Student Verification}

The student needs to place his NFC tag near the mobile phone. The application retrieves the information saved in the tag and verifies the student.

\section{Face Detection (JAVA+JSP)}

The student image will be captured and send to the backend detection module based on which a response of valid and invalid will be received by the mobile module.

\section{Attendance Marking}

On successful validation of the student, the application marks the attendance of the student in the application. This attendance is mark on the central server. Likewise, notification is also sent to the parents of the students for their reckoning.

\section{PARENTS MODULE \\ 1. View Attendance}

Using this module, the parents can see the attendance of their children in the application. They can view the attendance of their multiple child through one single interface.

\section{Attendance Analytics}

Using this module, the parents can compare the attendance of their children with other students in the class or the average attendance.

\section{FUTURE WORK}

The choice of example provided for an NFC system implementation is only with regard to a university campus this is because it is most suitable and easy to start. However, university and the education sector only make a small percentage of the commercial world of K.S.A. In kingdom of Saudi Arabia it provide services for whole this is long-term aim. Dr. Mohammed Mohandes created the Hajj Pilgrim Tracking and Identification system this design system allows the pilgrim to identify him of herself at checkpoints, shop using e-Wallet, and download guidance maps from particular access points. [2] Another good example is Electronic Point of Sales terminal (EPOS) where customers pay by using NFC enabled phones. This system operate in two major parts. The first one NFC enabled paymentterminals (PayPass terminal) provided by banks and second part is towards customer. The best example for this is Google Wallet application. This system is develop by Google for mobile payment that allows its user to store credit cards, loyalty cards, gift cards. Payments can be made fast and convenient by simply tapping the phone on any PayPassenabled terminal at checkout.

\section{CONCLUSION}

This paper customization of how system relaying on NFC technology may be developed. This system is easy, flexible, convenient and reliable which will extend by adding new modules. The tag which provide by colleges that have been employed for this system are NFC tag, and algorithm used that shown stable and reliable outcomes. Our study clearly defined the benefits of currently developed NFC applications by classifying them into NFC operating modes. For future developments of NFC- based application it will guide to believe that underlying each operating modes benefit by analysing already develop applications. 


\section{REFERENCES}

[1] NFC-Forum, Available: http://www.nfc-forum.org

[2] Rajesh S.Raut, Monika. Chauhan "Advanced Near Field Communication Technology (NFC)", Int. Journal of Information Technology \& Mechanical Engineering - IJITME, Vol.1 Issue. 3, March- 2014

[3] K. Fraser, T.Rodden, and C.O’Malley, "Home-school Technologies; Considering the Family," Proc. Of Interaction Design and Children (IDC 06), ACM Press, June 2006, pp. 153-156, doi: 10.1145/1139073.1139111.

[4] H. Jernstrom, "SiSSy - Smart-its child Surveillance System," Proc. The $4^{\text {th }}$ International Conference on Ubiquitous Computing (UbiComp '02), Springer, Sep. 2002, pp. 37-38, doi: 10.1145/1139073.1139111.

[5] R. Edwards and M. David, Children's understanding of parental involvement in education. Final Report: ESRC Research Grant, Award no. L129251012, 1999.

[6] San Francisco Chronicle: Students kept under supervision at school some parents angry over radio device. <http://www.sfgate.com/cgibin/article.cgi?file=/c/a/2005/02/10/BA DGES.TMP\&type $=$ printable $>13.07 .2009$.

[7] eSchoolNews: ACLU rips district's student-tracking pilot. <http://www.eschoolnews.com/news/top-news/index.cfm?i=51555>13.07.2009.

[8] Illuminati News: U.S. School District to Begin Microchipping Students. <http://www.illuminati-news.com/articles2/00231.html> 13.07.2009.

[9] J.Qvortrup, Children half price. Nordic childhood in social perspective (Born halv pris. Nordisk barndom I samfundsperspektiv). Espjerg, Denmark: Sydjysk Universitetsforlag, 1994.

[10] K. Rasmussen, Surveillance by webcams in day nurseries? (Kameraovervagning - I borns daginstitution?). Denmark: Institut for Uddannelsesforskning, Roskilde Universitetscenter, 2003.

[11] T. Fote, and T.U. Thomsen, "The Surveillance of Children's Mobility," Supervision \& Society, vol. 1, no. 4, Surveillance Studies Network, 2004, pp.535-554

[12] S.U. Jensen, and C.H. Hummer, Safe routes to school: an analysis of child road safety and travel (Sikre Skoleveje: en undersogelse af borns trafikisikkerhed og transportvaner). Denmark: Danmarks Transportforskning, 2002.

[13] M. Williams, O. Jones, C. Fleuriot, and L. Wood, "Children and Emerging Wireless Technologies: Investigating the Potential for Spatial Practice," Proc. Conference on Human Factor in Computing System (CHI '05), ACM Press, April 2005, pp. 819-828, doi: 10.1145/1054972.1055088.

[14] S. Aitken, The Geographies of Young People: The Morally Contested Spaces of Identity. London, UK: Routledge, 2001.

[15] F. Furedi, Paranoid Parenting. Harmondsworth, UK: Penguin Books Ltd., 2001.

[16] Guardian (Rayner, J.): Why this NSPCC advert is harmful to children.<http://www.guardian.co.uk/Archive/Article/0,4273,389064 00.html >13.07.2009. 